\begin{tabular}{|c|c|}
\hline Title & Space geodetic observations of repeating slow slip events beneath the Bonin Islands \\
\hline Author(s) & A risa, Deasy; Heki, Kosuke \\
\hline Citation & $\begin{array}{l}\text { Geophysical journal international, 210(3), 1494-1502 } \\
\text { https://doi.org/10.1093/pji/ggx258 }\end{array}$ \\
\hline Issue Date & 2017-09-01 \\
\hline Doc URL & http:/hdl.handle.net/2115/67742 \\
\hline Rights & $\begin{array}{l}\text { This article has been accepted for publication in Geophysical Journal International @: } 2017 \text { Deasy A risa and Kosuke } \\
\text { Heki Published by Oxford University Press on behalf of the Royal A stronomical Society. A Il rights reserved. }\end{array}$ \\
\hline Type & article \\
\hline File Information & GJI210 1494-1502.pdf \\
\hline
\end{tabular}

Instructions for use 


\title{
Space geodetic observations of repeating slow slip events beneath the Bonin Islands
}

\author{
Deasy Arisa and Kosuke Heki \\ Department of Natural History Sciences, Graduate School of Science, Hokkaido University, N10 W8 Kita-ku, Sapporo-city, \\ Hokkaido 060-0810, Japan.E-mail: arisadeasy@gmail.com
}

Accepted 2017 June 13. Received 2017 June 8; in original form 2016 September 19

\begin{abstract}
S UMMAR Y
The Pacific Plate subducts beneath the Philippine Sea Plate along the Izu-Bonin Trench. We investigated crustal movements at the Bonin Islands, using Global Navigation Satellite System and geodetic Very Long Baseline Interferometry data to reveal how the two plates converge in this subduction zone. These islands are located $\sim 100 \mathrm{~km}$ from the trench, just at the middle between the volcanic arc and the trench, making these islands suitable for detecting signatures of episodic deformation such as slow slip events (SSEs). During 2007-2016, we found five SSEs repeating quasi-periodically with similar displacement patterns. In estimating their fault parameters, we assumed that the fault lies on the prescribed plate boundary, and optimized the size, shape and position of the fault and dislocation vectors. Average fault slip was $\sim 5 \mathrm{~cm}$, and the average moment magnitude was $\sim 6.9$. We also found one SSE occurred in 2008 updip of the repeating SSE in response to an M6 class interplate earthquake. In spite of the frequent occurrence of SSEs, there is no evidence for long-term strain accumulation in the Bonin Islands that may lead to future megathrust earthquakes. Plate convergence in Mariana-type subduction zones may occur, to a large extent, episodically as repeating SSEs.
\end{abstract}

Key words: Plate motions; Satellite geodesy; Space geodetic surveys; Seismicity and tectonics; Dynamics and mechanics of faulting; Intra-plate processes.

\section{INTRODUCTION}

The Izu-Bonin-Mariana Arc occurs in the eastern margin of the Philippine Sea plate (PH), where the Pacific plate (PA) subducts westwards, and a series of small islands exist along the volcanic arc (Fig. 1a). The backarc of the Izu Islands, the northernmost part of this arc, is considered to be in the initial rifting stage, and Nishimura (2011) revealed its opening rate by space geodetic observations. Behind the Mariana Arc, to the south of the Izu-Bonin arc, mature active backarc spreading occurs (Kato et al. 2003). Behind the Bonin Islands, however, no active backarc spreading occurs (e.g. Tamaki 1985).

The Izu-Bonin-Mariana Arc is considered as one end member (Mariana 'type') in some classification of subduction zones (Uyeda \& Kanamori 1979), characterized by old, cold, and thick lithosphere, subducting at a high angle without large interplate thrust earthquakes. The PA-PH convergence rate is $\sim 4 \mathrm{~cm} \mathrm{yr}^{-1}$ around the Bonin Islands (Fig. 1b). There have been no historic megathrust earthquakes there, and we do not know if the plate convergence is accommodated episodically or steadily at this subduction zone.

Considering the lack of large earthquakes, episodic convergence may take a form of slow fault movements such as slow slip events (SSEs). Because fault slips in SSEs occur too slowly to radiate seismic energy, they are observable only with geodetic sensors. However, in Mariana-type subduction zones, coverage of the land area is usually insufficient for geodetic observations. In most of the Izu-Bonin-Mariana Arc, the volcanic arc is $\sim 200 \mathrm{~km}$ away from the boundary. Hence, it is difficult to detect crustal movements caused by locking and unlocking of the plate interface even if we can deploy modern space geodetic sensors on such volcanic islands. The Bonin Islands are located between the volcanic arc and the trench, offering a rare opportunity to monitor crustal movements $\sim 100 \mathrm{~km}$ from the trench at a Mariana-type subduction zone.

A clear SSE was first found in the Bungo Channel, Southwest Japan, with a dense array of Global Navigation Satellite System (GNSS) stations (Hirose et al. 1999). Later, similar SSEs were found to repeat fairly regularly every $\sim 6 \mathrm{yr}$ at the same fault patch (Hirose et al. 2012). Quasi-periodic recurrence is a general feature of these SSEs. For example, SSEs under the Boso Peninsula, Kanto District, Japan, another well-studied series of SSEs (Ozawa et al. 2003), recur every 5-7 yr, and those in the southwest Ryukyu Arc repeat biannually (Heki \& Kataoka 2008; Nishimura 2014). Outside Japan, repeating SSEs are found, for example, in Cascadia, Western North America (Dragert et al. 2001), Hikurangi, New Zealand (Douglas et al. 2005), and the Nicoya Peninsula, Costa Rica (Outerbridge et al. 2010). 

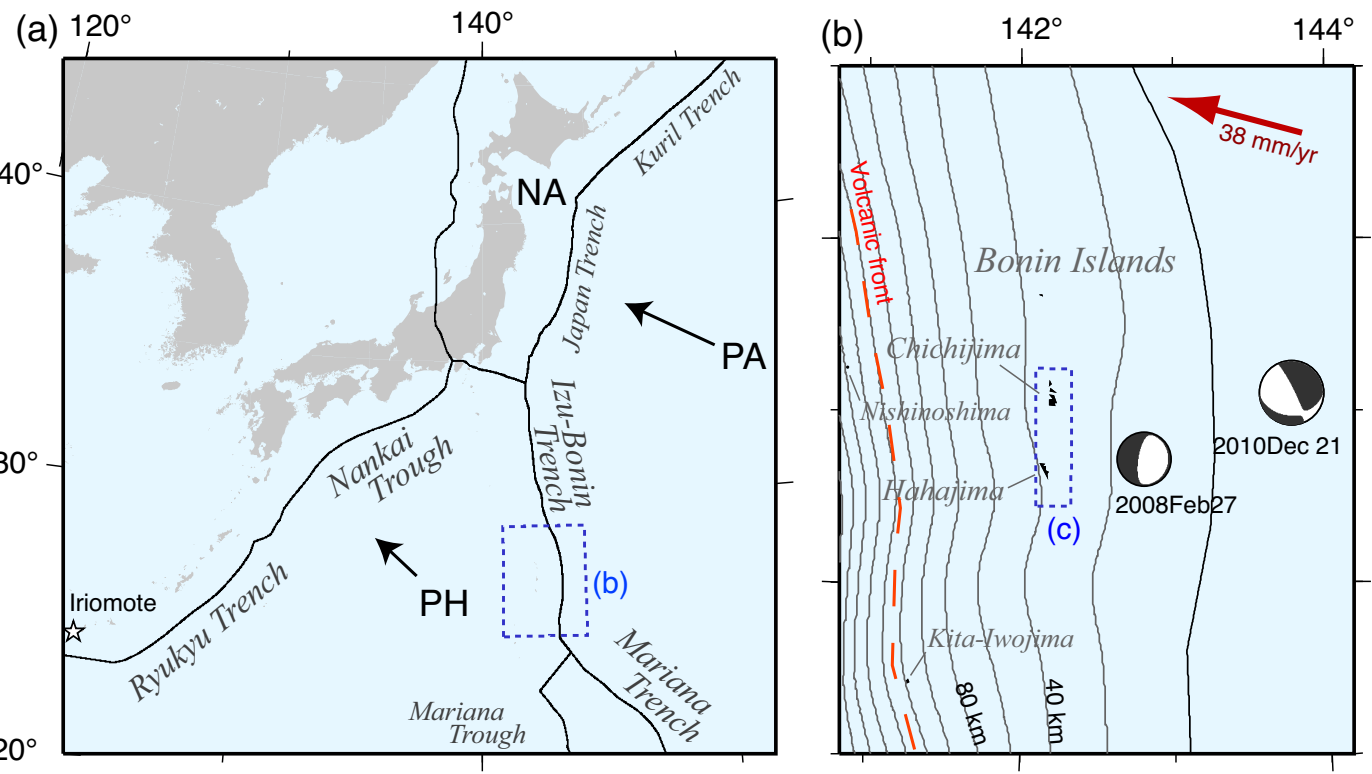

(c)

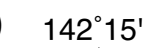

Figure 1. (a). Plate tectonic setting of the Japanese Islands. A star indicates the location of repeating SSEs beneath the Iriomote Island. The rectangle of blue dotted line shows the location of the Bonin Islands. It is magnified in (b), together with the epicentres of two regular earthquakes in the studied period $\left(M_{\mathrm{w}}\right.$ 6.2 on 2008 February 27, and $M_{\mathrm{W}} 7.4$ on 2010 December 22). Grey lines in (b) show depth contours of the PA slab surface (20 km interval). The arrow in (b) shows the time-averaged convergence of PA-PH of $\sim 3.8 \mathrm{~cm} \mathrm{yr}^{-1}$ from the MORVEL model (Argus et al. 2010). Chichijima and Hahajima constitutes the frontal arc located between the volcanic front (Nishinoshima and Kita-Iwojima are both volcanic islands) and the trench. A small rectangular region in (b) is magnified in (c), where we show positions of GNSS and VLBI stations in Chichijima and Hahajima.

\section{SPACE GEODETIC DATA IN THE BONIN ISLANDS}

\subsection{GNSS data}

The GNSS Earth Observation Network (GEONET) is the permanent dense array of GNSS receivers operated by Geospatial Information Authority of Japan (GSI). To analyse SSE signatures, we used the F3 solution (Nakagawa et al. 2009), available from terras.gsi.go.jp. Coordinate jumps associated with antenna replacements (occurring once in $\sim 10 \mathrm{yr}$ ) are provided by GSI, and we corrected for these steps before analysing the time-series for SSE signals.

Two GNSS stations were installed in Hahajima (960603) and Chichijima (942003) of the Bonin Islands (Fig. 1c) in 1990s. A new station in Chichijima (052007) started operation in 2007, but the older station (942003) stopped operation in 2011 March. The Hahajima station (960603) has been in operation throughout the studied period. Before 2007, the station coordinate time-series are noisy (Fig. 2a, inset), and the number of available stations is small. So we mainly analysed $\sim 10 \mathrm{yr}$ of data from 2007.0 to 2016.5 .

To reinforce the data set, we add data from another GNSS station located in Chichijima. This station was deployed by National Astronomical Observatory (NAO) of Japan, close to their radio telescope for astrometric Very Long Baseline Interferometry (VLBI). This data set spans from 2003 February to 2016 March, and the coordinate solution is based on the Precise Point Positioning technique (Zumberge et al. 1997). There was an antenna replacement in 2013, and a jump was estimated together with other parameters for SSEs.

We have four GNSS stations ( 3 from GEONET, 1 from NAO) to study the change of the coordinates (Fig. 2). The original coordinates are given in the International Terrestrial Reference Frame, and we removed the overall trend in Fig. 2 so that displacements related to SSEs and earthquakes appear as the departure from the horizontal lines. Standard deviations of the post-fit residuals were
2-4 mm for horizontal, and $8-10 \mathrm{~mm}$ for vertical components. The GEONET F3 solution is based on the baseline approach. The individual stations show smaller random noises, but the three stations often exhibit common systematic movements. On the other hand, the NAO GNSS coordinate time-series are devoid of such systematic noises, although their random noise is somewhat larger. For example, there are systematic disturbances in the second half of 2008 in GEONET stations. However, this is not seen in the NAO data, and we did not consider them to show real crustal movements.

\subsection{Displacement signatures in the GNSS data}

\subsubsection{Regular earthquakes}

According to the earthquake catalogue by Japan Meteorological Agency (www.jma.go.jp), there were two relatively large earthquakes in the studied period (2007-2016) and area (Fig. 1b), that is, (1) $M_{\mathrm{w}} 6.2$ inter-plate earthquake on 2008 February 27, and (2) $M_{\mathrm{w}} 7.4$ normal-fault outer rise earthquake on 2010 December 22. In Fig. 2(a), they are marked with dashed vertical lines. We cannot see significant steps for the first earthquake, but it is immediately followed by slow eastward movement, possibly due to afterslip or a triggered SSE that released much more seismic moment than the co-seismic slip (discussed later in Section 3.4). The second earthquake is associated with significant westward co-seismic steps at all the four stations (displacement vectors plotted on map in Fig. 3g) with no detectable post-seismic deformation signals.

\subsubsection{Repeating SSE signatures}

Generally speaking, GNSS sites at long distances from the trench limits the chances of detecting SSEs unless they are large. For example, we detected a large SSE $\left(M_{\mathrm{w}}>7.5\right)$, starting in 2004 July, 


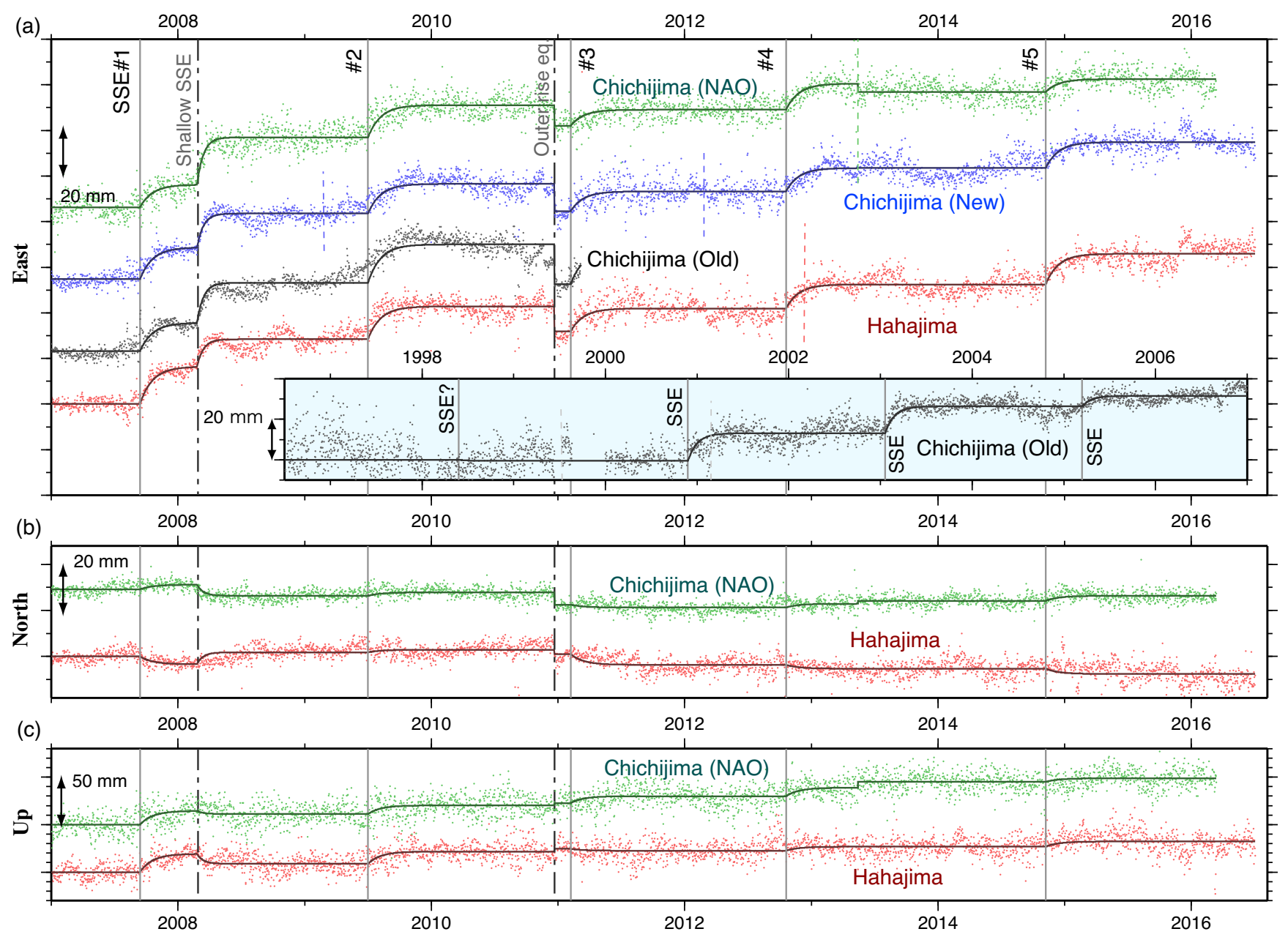

Time (year)

Figure 2. (a) East component of the coordinate changes of the four GNSS stations in the Bonin Islands (average trends during non-SSE periods are removed). The north and up components of the two GNSS stations are shown in (b) and (c), respectively. The five thick vertical grey lines show repeating SSEs (SSE\#1-\#5). The SSE starting in February 2008 is not counted as one of the repeating SSEs. The 2010 December normal fault (outer rise) earthquake caused westward jumps (vectors shown in Fig. 3g). Coordinate steps associated with antenna replacements, shown by short vertical dashed lines in (a), are corrected using values given a priori for the GEONET stations and estimated for the NAO station. In the inset of (a), east component time-series of the old Chichijima station 1996-2007 show four more possible SSEs.

in the northernmost part of the Izu-Bonin Arc (Arisa \& Heki 2016) at the Izu Islands $\sim 200 \mathrm{~km}$ away from the trench. $M_{\mathrm{w}} 7$ class SSEs, if any, would not have been caught by GNSS stations there. The Bonin Islands are located only $\sim 100 \mathrm{~km}$ from the trench (Fig. 1b), and we expect to detect $M_{\mathrm{w}} 7$ class SSEs there.

In addition to the changes in east components of four GNSS stations in the Bonin Islands (Fig. 2a), we show north (Fig. 2b) and vertical (Fig. 2c) coordinate changes for two of the stations. There we removed the overall inter-SSE trends, composed of rigid movement of PH and inter-SSE strain accumulation. There, SSE signatures appear as episodic slow eastward movements, whose onsets are marked with thick grey vertical lines as SSE\#1-\#5. Their typical cumulative displacements are 1-2 cm, and each event lasts for a few months. Fig. 2 shows that displacements are mostly eastwards, with small but significant north and up components.

We modelled the displacement $u$ caused by SSE using an exponential function of time $t(t=0$ at the onset of SSE), that is, $u=A[1-\exp (t / \tau)]$. The time constant $\tau$ for each event is optimized by grid search with $0.01 \mathrm{yr}$ step using the east component, and the cumulative displacements $A$ are estimated in all the three components using the same time constants. This resulted in $0.10 \mathrm{yr}$ uniform time constants for all SSEs, except somewhat shorter time constant ( $\tau=0.05 \mathrm{yr}$ ) for the $2008 \mathrm{SSE}$. We optimized the SSE onset times also by the grid-search method.

These five SSEs started approximately in (1) August 2007, (2) July 2009, (3) February 2011, (4) October 2012 and (5) November 2014. They have recurrence intervals of 20-25 months, with the average of $\sim 1.8 \mathrm{yr}$. We could not find any earthquakes that may have triggered these five SSEs. The cumulative horizontal displacement vectors plotted in the map (Figs 3a-f) are fairly uniform, and ranged from 12 to $17 \mathrm{~mm}$. The error ellipses attached to the vectors reflect the standard deviations of the parameter $A$, scaled with the postfit residuals in the coordinate time-series shown in Fig. 2. The displacement vectors of the three Chichijima GNSS stations often differ significantly from each other, suggesting that these errors are underestimated.

The GNSS stations in Chichijima moved mostly eastwards, with small amounts of north components. In contrast to Chichijima stations, Hahajima showed south and east displacements. In Fig. 3(h), we show the average displacements of five repeating SSEs (the old 

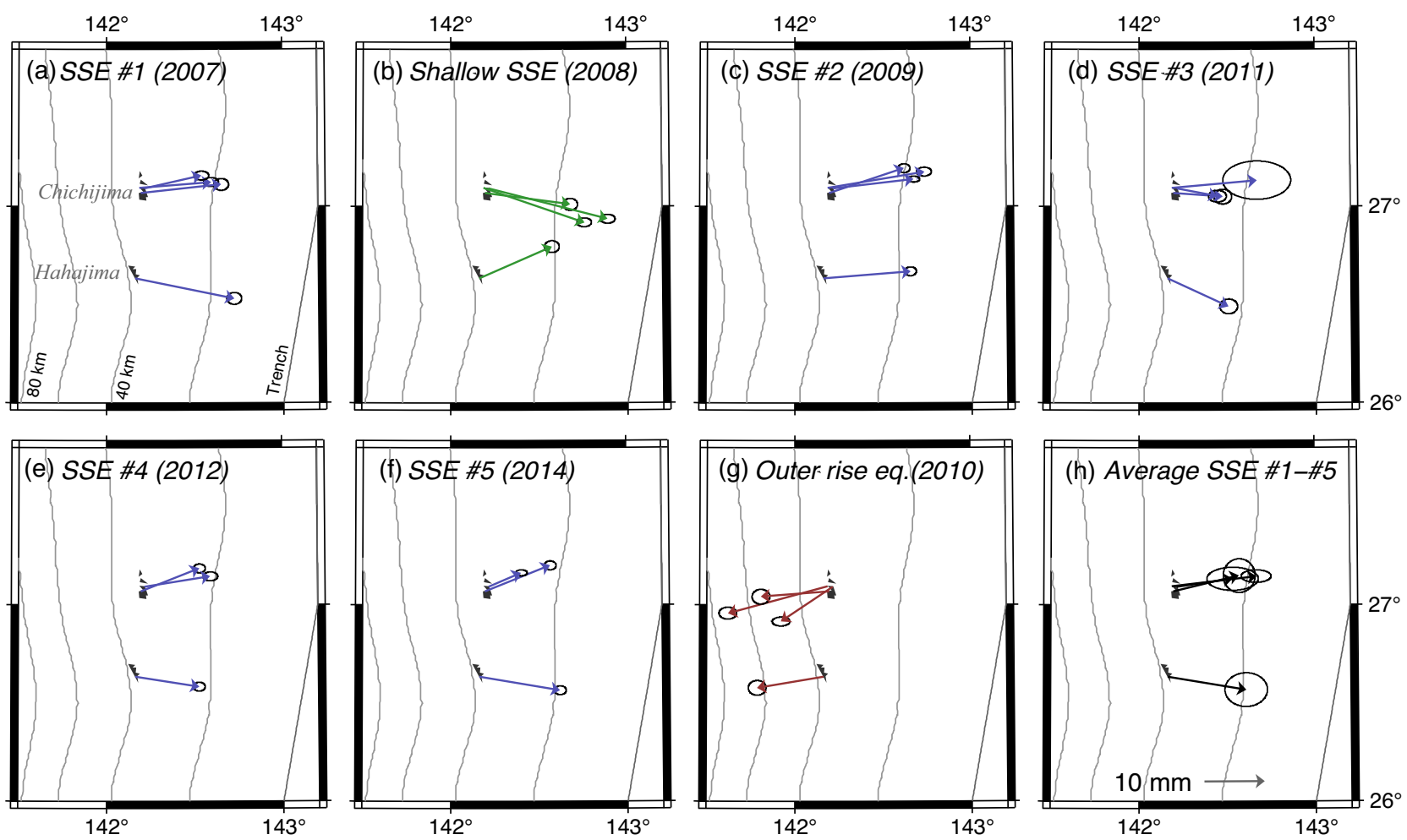

Figure 3. (a-e) The cumulative horizontal displacement vectors of GNSS stations in the six SSEs from 2007 to 2014 shown in Fig. 2. Error ellipses are derived from the time-series analysis, and show $2 \sigma$. All SSEs (except the 2008 one) show similar displacement patterns, and are repeating SSEs. Average displacement of the five repeating SSEs are shown in (h), where the error ellipses indicate the standard deviation of the displacement vectors of the five events (the old Chichijima station covers only three SSEs). In (g) we show coseismic steps of the 2010 outer rise earthquake.

Chichijima station had data of only three SSEs). We discuss fault models in Section 3.1 using these average vectors.

The 2008 SSE show different patterns in horizontal displacements (Fig. 3b), that is, Chichijima/Hahajima showed southward/northward displacements (respectively) in addition to east components. This reflects the difference in the slipped fault patch between the 2008 SSE and all other repeating SSEs. The 2008 SSE is therefore discussed separately in Section 3.4. The displacement vectors in the 2011 SSE are somewhat different from the other four repeating SSEs (Fig. 3d). This is probably due to the co-seismic step by the 2010 December $22 M_{\mathrm{w}} 7.4$ outer rise earthquake (Fig. $3 \mathrm{~g}$ ). Because the two events are separated by only $\sim 2$ months, it was difficult to discriminate the cumulative displacements in the 2011 February SSE from the co-seismic steps of the 2010 December earthquake.

\subsection{VLBI data (VERA)}

To reinforce GNSS results in the Bonin Islands, we examine distance change time-series between the VLBI stations at Chichijima and two other VLBI stations in SW Japan 2004.8-2015.4 (Fig. 4a). In the Bonin Islands, first VLBI observations were carried out in 1980s using a mobile radio telescope to detect the movement of PH (Matsuzaka et al. 1991). A new permanent VLBI station was installed in Chichijima in 2003, which constitutes a part of the VERA (VLBI Exploration of Radio Astrometry) array together with the other three stations, Mizusawa, NE Japan, Ishigaki in the Ryukyu Islands, and Iriki, Kyushu (Fig. 4b).

Since 2004, routine geodetic VLBI observing sessions have been performed every $1-2$ weeks in addition to astrometric observations.
Because the observations are not so dense in time as GNSS, the VLBI data are less suitable for SSE studies than the GNSS data. In Fig. 4(a), we plot the baseline length (distance) time-series of Chichijima-Iriki and Chichijima-Ishigaki pairs. There, we assumed the same onset times and time constants of the SSEs as the GNSS data. The VLBI data show similar SSE signatures and co-seismic steps to the GNSS data. It also suggests another SSE in 2005, not included in the GNSS data in Fig. 2. The Ishigaki station is considered to move by SSEs repeating biannually beneath the Iriomote Island (Fig. 1a; Heki \& Kataoka 2008). These SSEs let the Ishigaki station move southeastwards by up to $1 \mathrm{~cm}$, and would contribute to the increase of the scatter in the Chichijima-Ishigaki baseline length time-series.

\section{FAULT MODELS}

\subsection{The repeating SSEs}

Here we infer fault parameters to explain the observed average displacements of the repeating SSEs. We use Okada's (1992) equations to calculate surface displacements due to a dislocation of a rectangular fault in elastic half-space. In general, we prescribe parameters such as the location (latitude, longitude and depth), orientation (dip and strike), dimension (width and length) and slip vector (vector length and rake) of the fault. With a larger number of GNSS stations of sufficient spatial coverage, for example, in the case of the Bungo Channel, we could perform an inversion analysis of the time-variable fault slips (e.g. Yoshioka et al. 2015). In the present case, however, spatial coverage of the observed displacement vectors is limited (i.e. two small islands), and we have to assume a 
(a)

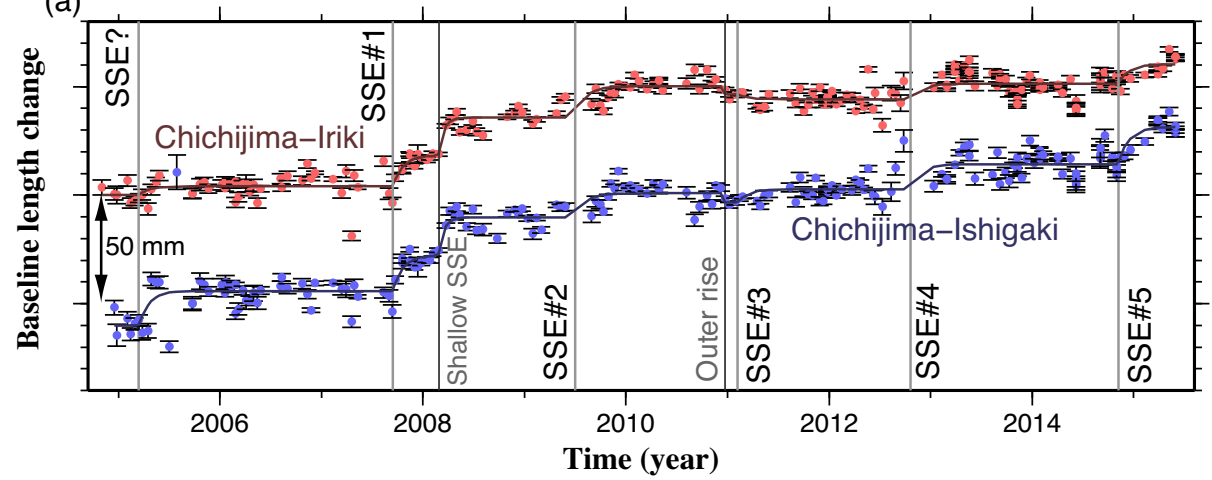

(b)

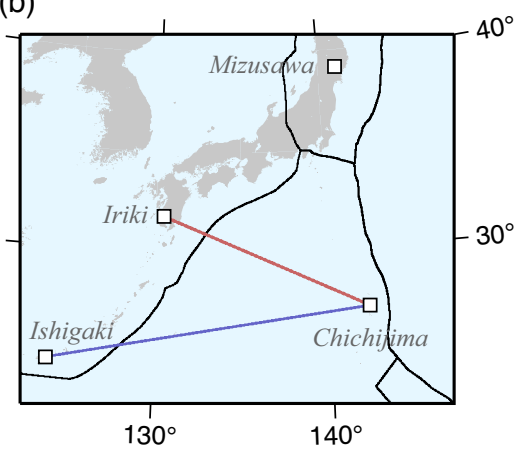

Figure 4. (a) Baseline length change 2004-2015 from the two pairs of the VERA VLBI stations (Chichijima-Iriki, Chichijima-Ishigaki). We fit the time-series with the same model as the GNSS data (Fig. 2). (b) The map shows the positions of the four VLBI stations and baseline vectors used in this study.

(a)

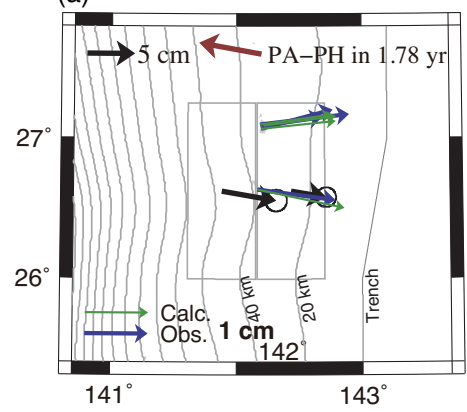

(b)

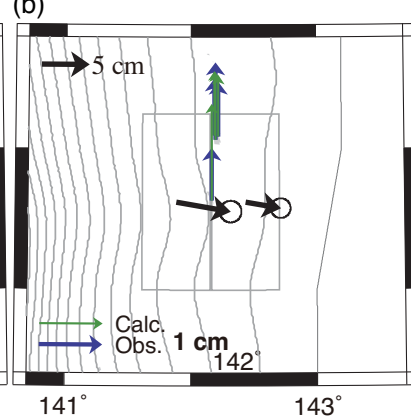

(c)

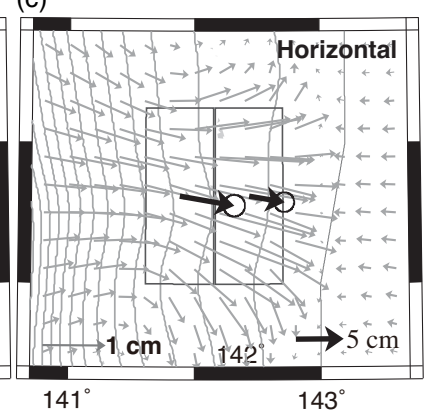

(d)

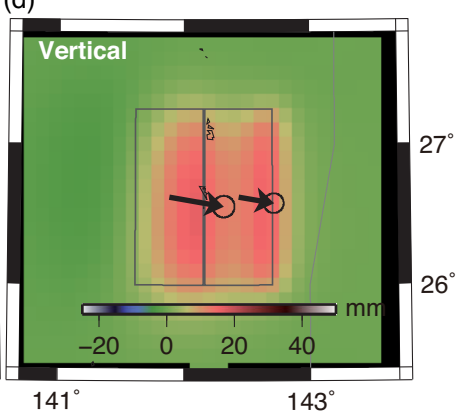

Figure 5. Fault estimation for the average of the 5 repeating SSEs 2007-2014. Double rectangles in all panels are the surface projections of the assumed fault patches. Thick arrows show the slips estimated by least-squares method using the 3-D displacement vectors of the four GNSS stations (2 $\sigma$ errors are scaled a posteriori using post-fit residuals). (a) and (b) show horizontal and vertical displacements of GNSS stations, respectively. In (c) and (d), horizontal and vertical displacements calculated at grid points are shown with light grey arrows and with colours (red shows uplift), respectively. The red arrow in (a) indicates the PA motion relative to $\mathrm{PH}$ over the average interval of the SSE recurrence $(\sim 1.8 \mathrm{yr})$.

simple geometry of the fault for all the SSEs. We assumed two rectangular patches along the dip direction (to enable increasing dip with depth), and estimated the fault slip by least-squares method using the 3-D displacement vectors of all the GNSS stations.

In order to reduce the number of parameters to be optimized, we confined the faults to lie on the PA slab surface. Hence, if we give the horizontal position of the fault centres, the orientation (strike and dip) and the depth of the faults are given a priori from a numerical model of the slab surface (earthquake.usgs.gov/data/slab). We also fixed the slip direction to that of the PA-PH convergence predicted by the MORVEL model (Argus et al. 2010). We inferred the remaining four parameters by grid-search, i.e. the north-south dimension (length), the east-west dimension (width), and the alongstrike (nearly north-south) and along-dip (nearly east-west) positions of the fault centre. For the average displacement vectors (Fig. 3h), the optimized model had length and width of 140 and $120 \mathrm{~km}$, respectively. The estimated slips were $5.8 \pm 1.0 \mathrm{~cm}$ and $3.8 \pm 0.8 \mathrm{~cm}$ for the deeper and the shallower fault patches, respectively. The errors of the estimated slips $(2 \sigma)$ are scaled using the post-fit residuals of the displacement vectors, and not influenced by the underestimation of the errors of the individual displacement vectors. The time-averaged plate convergence is $\sim 3.8 \mathrm{~cm} \mathrm{yr}^{-1}$ beneath the Bonin Islands according to the MORVEL model (Argus et al. 2010). Hence, the average of the estimated slips corresponds to $\sim 70$ per cent of the cumulative plate convergence over the average recurrence interval $(\sim 1.8 \mathrm{yr})$.

\subsection{Ambiguity in the fault geometry}

Fig. 6 shows the detail of the grid search of the four parameters. In Figs 6(a)-(f), we show the behaviours of the root-mean-squares (RMS) of the post-fit residuals of the displacement vectors by changing two of the four parameters (the other two parameters were fixed to the optimal values). The blue indicates small RMS, and the red indicates large RMS. Concentration of the blue in a small region near the centre of the figure implies that the parameters are well constrained (e.g. E-W position and fault length in Fig. 6e). Elongation of the blue region along a certain axis shows the difficulty in constraining that parameter. If the blue region elongates diagonally, the two parameters are correlated.

We prohibited the parameter combinations requiring unrealistic fault slips. If either one of the estimated slips of the two faults exceeds the cumulative PA-PH convergence over the average recurrence interval, we consider that parameter combination is unrealistic and pasted that combination with white. We did the same if the estimated slips were negative. The RMS behaviours for these parameter combinations are simple, and we confirmed that there are no "local minima" that often occur in multi-parameter grid searches.

From the six panels of Fig. 6, we recognize two problems in constraining the four parameters. The first problem is the strong negative correlation between the fault length and the NS position (Fig. 6c). Fig. 6(c) shows that, even if we move the fault centre southwards by $1 \mathrm{~km}$, we can fit the observed data by increasing the fault length by $2 \mathrm{~km}$. This simply means that the south end 

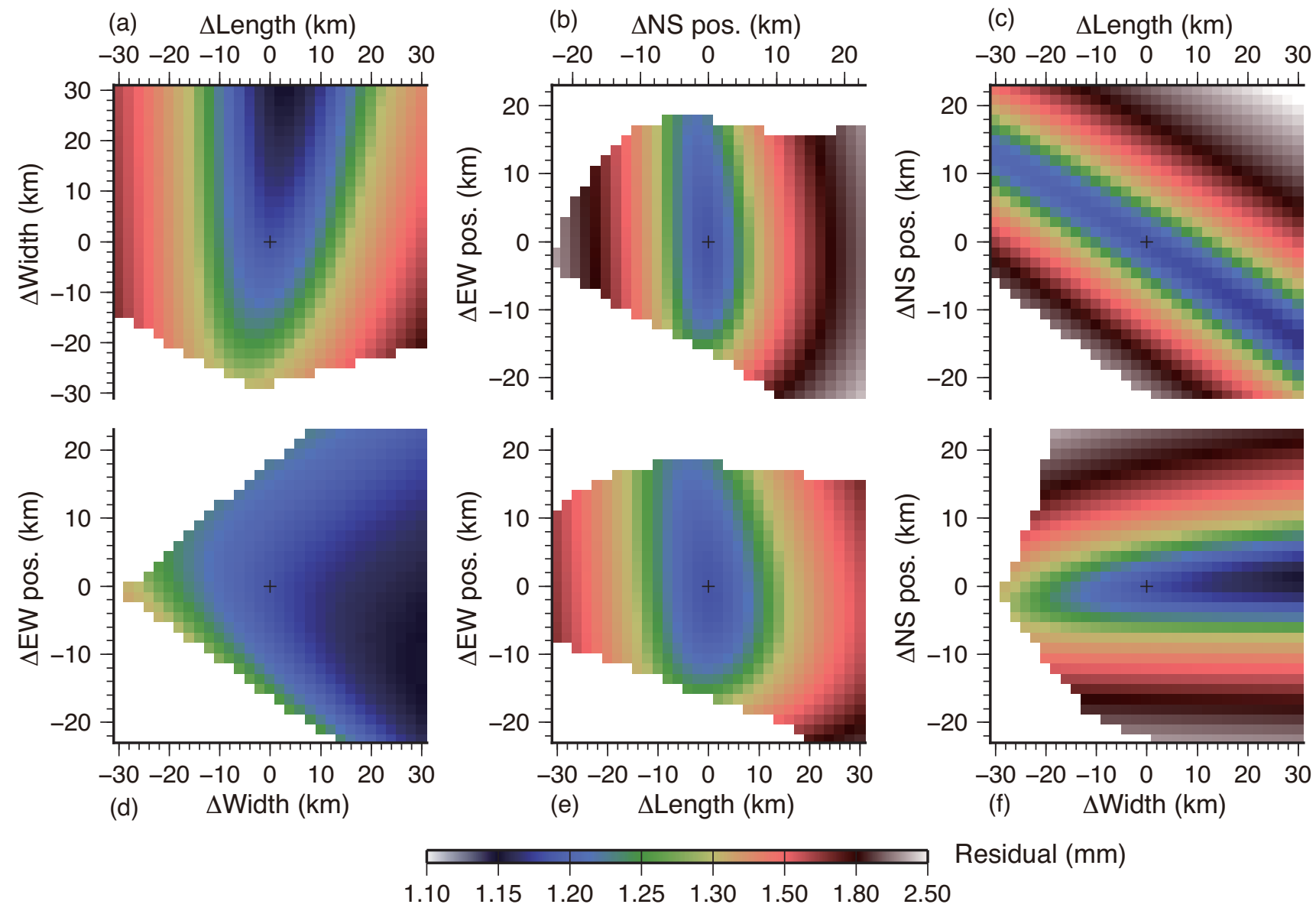

Residual (mm)

Figure 6. In the grid search, we optimized the four parameters (NS and EW position, width and length) of the fault so that the combination of the parameters shows least root-mean-squares (RMS) of post-fit residuals of the average SSE displacement field (Fig. 5). Other quantities, such as the strike/dip, depth, and slip direction are given a priori assuming that the SSE occurred between PA and PH at their boundary. The six panels show 2-D distribution of the residual for various combinations out of the four parameters, that is, length and width (a), NS and EW position (b), length and NS position (c), EW position and width (d), EW position and length (e), and NS position and width (f). They are all given as the deviations from the nominal values shown in Fig. 5. If a particular combination of the parameters required the slips of either of the faults above the $1.8 \mathrm{yr}$ plate convergence or below zero, we pasted that combination in white.

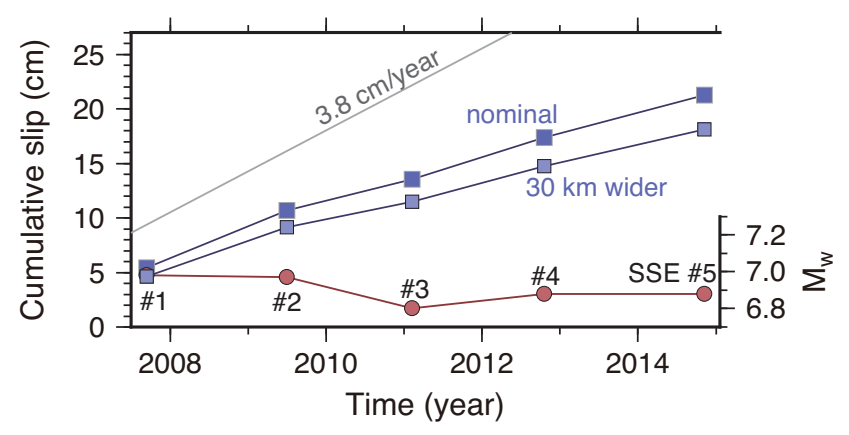

Figure 7. Cumulative slip (weighted average of the slips of the two fault patches) of SSEs \#1-\#5 shown with blue squares is compared with the average PA-PH plate convergence rate in this region $\left(\sim 3.8 \mathrm{~cm} \mathrm{yr}^{-1}\right)$. We also show the slip accumulation when we expanded the width of the faults by $30 \mathrm{~km}$. Red circles show the $M_{\mathrm{w}}(6.8-7.0)$ of individual SSEs. The faults $30 \mathrm{~km}$ wider require slips $\sim 15$ per cent smaller, but $M_{\mathrm{w}}$ is insensitive to this change ( $M_{\mathrm{w}}$ for the $30 \mathrm{~km}$ wider case are not shown).

of the fault cannot be constrained, i.e. the fault can extend southwards without degrading the fit to the observed displacements. However, this ambiguity does not imply the uncertainty in the slips, i.e. the cumulative slip shown in Fig. 7 hardly depends on the posi- tion of the south end (although $M_{\mathrm{w}}$ depends on the south end of the fault).

Another problem is the uncertainty in the fault width. Figs 6(a), (d), and (f) suggest that this parameter is not much correlated with other parameters, but any widths exceeding $120 \mathrm{~km}$ equally realize a good fit to the observations. The two islands line up along strike just above the fault, and their displacements are simply insensitive to the fault width. Unlike the southern boundary discussed in the previous paragraph, the width is negatively correlated with the slip. Here we showed the slip accumulation for the two cases, $120 \mathrm{~km}$ (approximate depth range 20-60 km) and $150 \mathrm{~km}$ (approximate depth range $10-70 \mathrm{~km}$ ) in Fig. 7. We think the fault width exceeding $150 \mathrm{~km}$ rather unlikely because it requires the downdip end of the fault deeper than $70 \mathrm{~km}$. The estimated $M_{\mathrm{w}}$ of the average SSE was $\sim 6.9$ (the rigidity is assumed as $40 \mathrm{GPa}$ ). The $M_{\mathrm{w}}$ and the duration of SSE (a few months) is consistent with the scaling law by Ide et al. (2007) that the moment release of slow earthquakes are proportional to their durations.

\subsection{Recurrence of SSE}

Next, the fault model of the average SSE is applied to individual SSEs (i.e. each SSE is assumed to rupture the same patch in the 
(a)

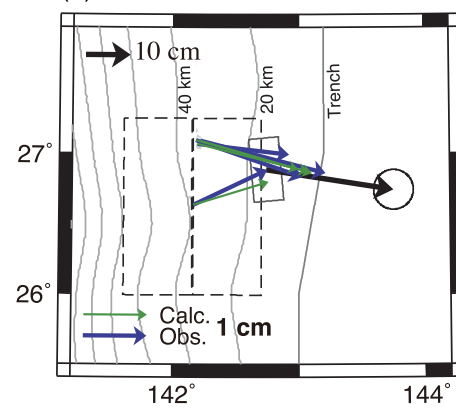

(b)

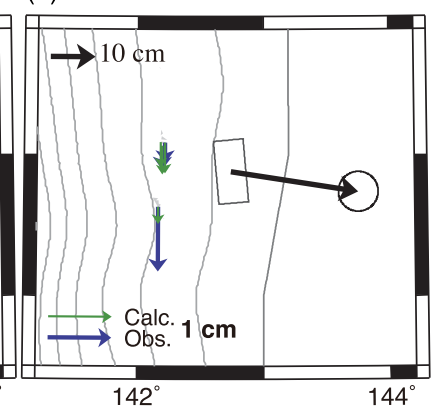

(c)

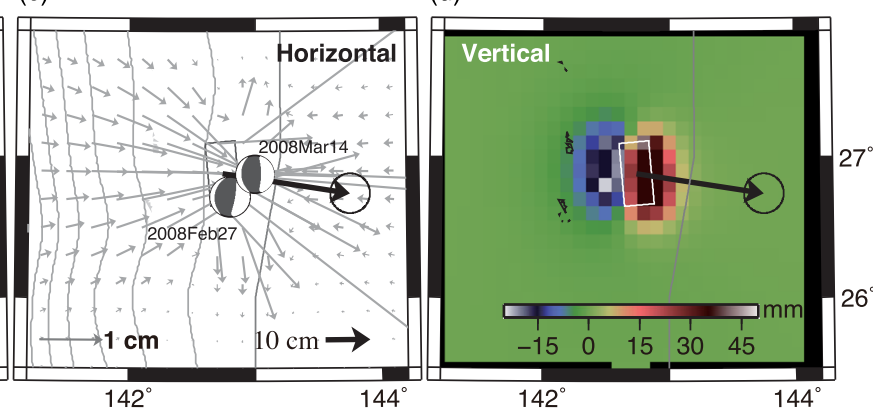

Figure 8. Fault model of the shallow SSE that started in February 2008. For the detail of the four panels, see the caption of Fig. 5. For comparison, we show faults of the repeating SSEs with dashed lines in (a). In (c), we show mechanisms of the two interplate earthquakes that occurred at the onset of the SSE (February 27, $M_{\mathrm{W}} 6.2$ ) and during the SSE (March 14, $M_{\mathrm{W}}$ 6.0). GNSS time-series did not present significant steps related to these two earthquakes.

same direction), and we estimated the lengths of the slip vectors. By comparing the slips for the fault widths of 120 and $150 \mathrm{~km}$ in Fig. 7, the slip in the latter case is found to be $\sim 15$ per cent less than the former. However, the both cases give similar $M_{\mathrm{w}}$ (not shown in Fig. 7). The slips of individual SSEs are fairly uniform. This may reflect, to some extent, the mechanical isolation of this SSE patch from other seismogenic plate interface. The rhythm of some repeating SSEs in the Japanese mainland, such as those under the Boso Peninsula, was disturbed by the 2011 Tohoku earthquake (Hirose et al. 2012; Ozawa 2014). On the other hand, the Bonin Island SSEs (Fig. 7) are not disturbed by this earthquake.

Information on the recurrence of the SSEs before 2007 is limited. However, the inset of Fig. 2(a) suggests that similar SSEs have occurred in 2005 March, 2003 January, 2000 November, and possibly in the middle of 1998. This suggests that the average recurrence interval before 2007 was $\sim 2.3 \mathrm{yr}$, somewhat longer than $\sim 1.8 \mathrm{yr}$ after 2007.

\subsection{SSE following an earthquake in 2008 February 27}

As we recognized earlier, there was an SSE in 2008 (Fig. 2b), but this was not counted as one of the repeating SSEs in the Bonin Islands because of its different displacement pattern (Fig. 3b). This SSE started following an $M_{\mathrm{w}} 6.2$ earthquake on 2008 February 27, at the PA-PH boundary (Fig. 1b.).

We followed the same procedure as the average of the repeating SSEs to infer the fault geometry and slip. We found that the slipped fault is located at the updip side of the repeating SSE fault patch (Fig. 8a). A fault length of $50 \mathrm{~km}$ and width of $25 \mathrm{~km}$, and the dip of $20^{\circ}$ can reproduce the observed displacements well (Fig. 8). The fault slip in this SSE is $28.9 \pm 3.6 \mathrm{~cm}$ towards N99E. This is approximately six times as large as the deeper repeating SSEs, and represents $\sim 8$ yr's worth of plate motion.

Fig. 9 shows the results of the similar grid search to the average repeating SSE in Fig. 6. In addition to the a priori constraints in the average SSE (a fault plane confined within the slab surface slips in the PA-PH convergence direction), we fixed the ratio between length and width to $2: 1$ because we could not constrain it with the existing data. Fig. 9 shows that the remaining three parameters (EW and NS positions, and fault length) are rather well constrained without serious mutual correlations. Among the three parameters, the length is less well constrained. Fig. 9(d) shows how the change in the length influences the estimated slip.

On the other hand, $M_{\mathrm{w}}$ of this SSE is little influenced by the fault length, and is $\sim 6.7$. This is somewhat smaller than the repeating
SSE, but is much larger than the February 27 earthquake of $M_{\mathrm{w}}$ 6.2. There was another $M_{\mathrm{w}} 6.0$ earthquake during the SSE (2008 March 14), with epicentre close to the updip end of the slipping patch (Fig. 8c). It is known that SSEs are often accompanied by regular earthquakes with magnitudes up to M5, for example, in the Boso Peninsula (Ozawa et al. 2007) and in Hikurangi (Wallace et al. 2012). In the 2008 case, the $M_{\mathrm{w}} 6.2$ February earthquake would have triggered the SSE, and then the SSE encouraged the occurrence of the $M_{\mathrm{w}}$ 6.0 March earthquake. Because the SSE occurred in a similar fault patch to the February earthquake, this slow slip could also be interpreted as a large afterslip of this earthquake.

\section{DISCUSSION AND CONCLUSION}

\subsection{Absence of long-term compressional strain accumulation}

We removed the general inter-SSE trend from the time-series shown in Fig. 2, and this makes it difficult to see the balance between buildup and release of compressional strain near the plate boundary. To see them, we need to monitor the movement of the Bonin Islands in the reference frame fixed to the stable interior of PH. However, this is difficult because there are not enough GNSS points on its stable interior. Instead, in Fig. 10, we show the time-series of the distance from the Hahajima and Chichijima GNSS stations to three stations in the stable interior of $\mathrm{PH}$, that is, North-Daito, SouthDaito, and Okinotorishima. The Daito and the Bonin Islands are located in similar latitudes, and the changes in these distances would depict inter-SSE strain build-up and co-SSE release as decrease and increase, respectively, without being impacted by possible reference frame issues.

Although the time-series show many undulations due mainly to repeating SSEs, their overall trend over the last $20 \mathrm{yr}$ do not show net shortening (there might be small distance increase, but it is less than $2 \mathrm{~mm} \mathrm{yr}^{-1}$ ). This has important implications for the accommodation of plate convergence near the Bonin Islands. The first point is the lack of obvious long-term strain build-up for future megathrust earthquakes. Small amount of interplate coupling at the Izu-Bonin Trench continuously build up compressional strain near the plate boundary, but in the area of the Bonin Islands such strain is regularly released by biennial SSEs as observed in this study. There should be secular build-up of strain at less than 20 $\mathrm{km}$ depth on the plate interface, as suggested by the occurrence of the 2008 SSE. The full coupling in this depth range would let the Bonin Islands move towards WNW by $\sim 5.5 \mathrm{~mm} \mathrm{yr}^{-1}$ (Fig. 10), 

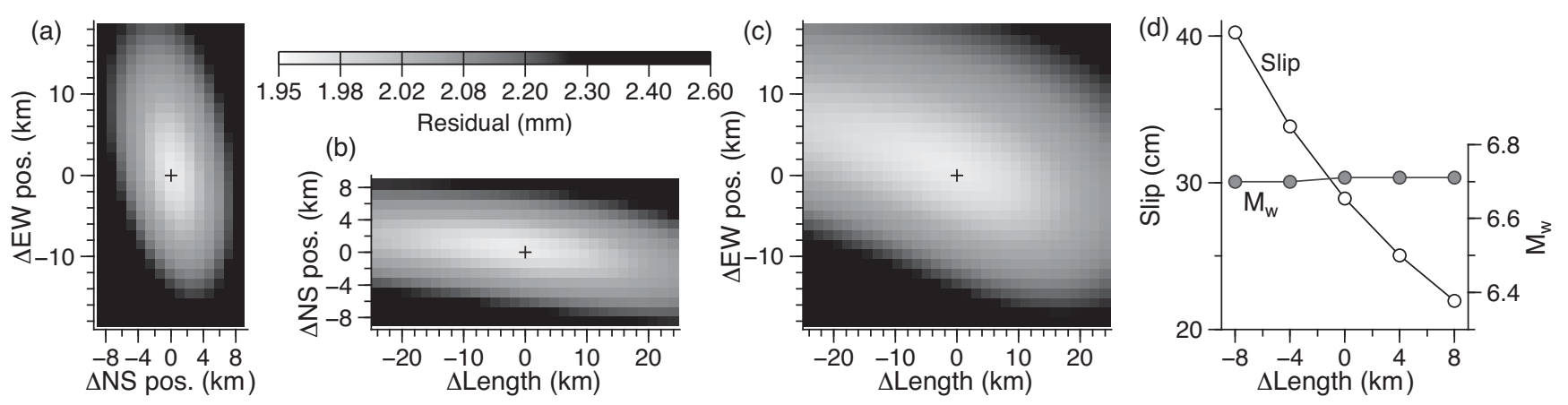

Figure 9. For the 2008 SSE, we did similar grid search to Fig. 6, for three combinations (a-c) of the three parameters. Here we fixed the fault width to a half of the length, and optimized the three parameters, NS and EW position, and fault length. Because the current network cannot well constrain the length, we gave in (d) the relationship between the change in length $( \pm 8 \mathrm{~km})$ and the estimated slip and resultant $M_{\mathrm{w}}$.

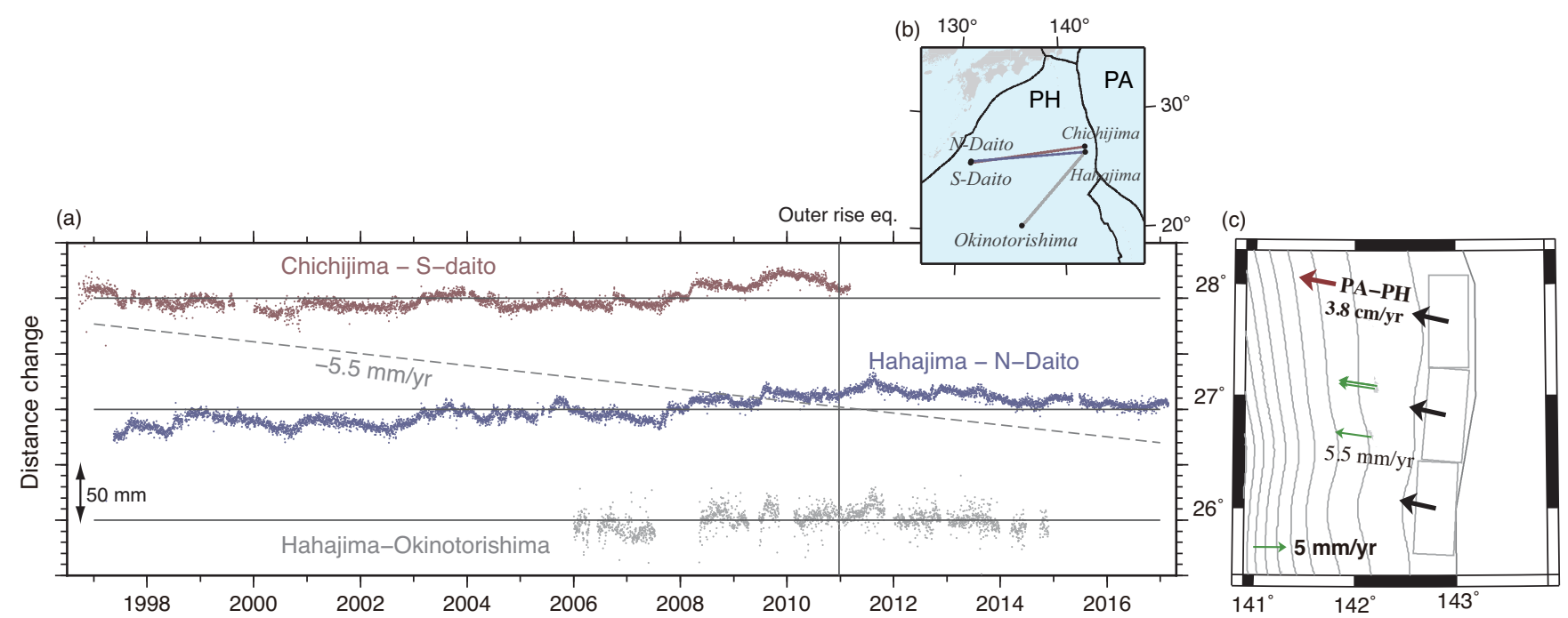

Figure 10. (a) Time-series of the distance between stations in the Bonin Islands (Chichijima and Hahajima) and three GNSS stations on the stable interior of PH (North- and South-Daito Islands, and the Okinotorishima Island). A grey vertical line shows the 2010 December outer rise earthquake, whose co-seismic steps are removed. For the station positions, see the map (b). The map is drawn with a Mercator projection using the pole at the PA-PH Euler pole. Hence, PH movement appears as a leftward motion parallel with the frame. In spite of short-term undulations reflecting the SSEs, overall distance changes are negligible, suggesting that little long-term elastic strain accumulation takes place in this plate boundary. In (c), we show that if the shallow part (0-20 km in depth) of the plate interface was fully coupled, the Bonin Islands would move by $\sim 5.5 \mathrm{~mm} \mathrm{yr}^{-1}$ towards WNW. As seen in (a), this is not the case.

and this is not the case. Hence, the coupling at this depth would be partial, and both stable sliding and occasional shallow SSEs would accommodate the plate convergence there.

Secondly, this justifies the use of the Hahajima GNSS station to define the Euler vector of the stable part of PH (Arisa \& Heki 2016). Over the time scales of a few decades, we can assume that the Bonin Islands are fixed to the stable interior of PH. The lack of significant extensional strain also means that active backarc rifting does not occur in this portion of the Izu-Bonin-Mariana Arc.

\subsection{Concluding remarks}

We analysed GNSS data over the last 10 yr (2006-2016), and confirmed the occurrence of five repeating SSEs, with $M_{\mathrm{w}} 6.8-7.0$, beneath the Bonin Islands, with the depth range not well constrained but possibly $20-60 \mathrm{~km}$ or wider, with a recurrence interval of $\sim 2$ yr. These SSEs were fairly uniform in recurrence intervals, time constants, and displacements. Apart from these repeating SSEs, we found an occurrence of another type of SSE with $M_{\mathrm{w}} 6.8$ updip of the deeper repeating SSEs, following an $M_{\mathrm{w}} 6.2$ interplate earthquake on 2008 February 27. We also confirmed the lack of significant long-term compressional strain accumulation, which is consistent with the absence of historical megathrust earthquakes in this subduction zone.

These observations demonstrate that the plate convergence beneath the Bonin Islands is accommodated significantly by repeating SSEs. The Bonin Islands are exceptional in the Izu-Bonin-Mariana system for their short distance $(\sim 100 \mathrm{~km})$ from the trench. Emergence of such a frontal arc might be due to the collision of the Ogasawara Plateau on PA with the arc, and this makes it uncertain how far the Bonin Islands represent Mariana-type subduction zones in general. Deployment of seafloor geodetic benchmarks and frequent measurements, as was done off the Pacific Ocean coast of the Japanese Islands (e.g. Yokota et al. 2016), would eventually solve the problem in the future.

\section{ACKNOWLEDGEMENTS}

We thank Geospatial Information Authority of Japan for the F3 solution of the GEONET data. We obtained the GNSS and VLBI 
data of the VERA network from Yoshiaki Tamura and Takaaki Jike, National Astronomical Observatory of Japan, which is gratefully acknowledged. The paper has been improved by constructive reviews by Laura Wallace and an anonymous referee, and the editor Duncan Agnew.

\section{REFER E N CES}

Argus, D.F., Gordon, R.G. \& DeMets, C., 2010. Geologically current motion of 56 plates relative to the no-net-rotation reference frame, Geochem. Geophys. Geosyst., 12, doi:10.1029/2011GC003751.

Arisa, D. \& Heki, K., 2016. Transient crustal movement in the northern Izu-Bonin arc starting in 2004: a large slow slip event or a slow back-arc rifting event?, Tectonophys, 682, 206-213.

Douglas, A., Beavan, J., Wallace, L. \& Towend, J., 2005. Slow slip on the northern Hikurangi subduction interface, New Zealand, Geophys. Res. Lett., 32, L16305, doi:10.1029/2005GL023607.

Dragert, H., Wang, K. \& James, T.S., 2001. A silent slip event on the deeper Cascadia subduction interface, Science, 292, 1525-1528.

Heki, K. \& Kataoka, T., 2008. On the biannualy repeating slow slip events at the Ryukyu Trench, Southwest Japan, J. geophys. Res., 113, B1140, doi:10.1029/2008JB005739.

Hirose, H., Hirahara, K., Kimata, F., Fujii, N. \& Miyazaki, S., 1999. A slow thrust slip event following the two 1996 Hyuganada earthquakes beneath the Bungo Channel, southwest Japan, Geophys. Res. Lett., 26(21), 32373240 .

Hirose, H., Kimura, H., Enescu, B. \& Aoi, S., 2012. Recurrent slow slip event likely hastened by the 2011 Tohoku earthquake, Proc. Natl. Acad. Sci. USA, 109, 15 157-15 161.

Ide, S., Beroza, G.C., Sherry, D.R. \& Uchide, T., 2007. A scaling law for slow earthquakes, Nature, 447, 76-79.

Japan Meteorological Agency, 2010. Monthly report on earthquakes and volcanoes in Japan, December 2010, pp. 32-35.

Kato, T., Beavan, J., Matsushima, T., Kotake, Y., Camacho, J.T. \& Nakao, S., 2003. Geodetic evidence of back-arc spreading in the Mariana Trough, Geophys. Res. Lett., 30, 1625, doi:10.1029/2002GL016757.

Matsuzaka, S., Tobita, M., Nakahori, Y., Amagai, J. \& Sugimoto, Y., 1991. Detection of Philippine Sea Plate motion by very long baseline interferometry, Geophys. Res. Lett., 18, 1417-1419.
Nakagawa, H. et al., 2009. Development and validation of GEONET new analysis strategy (version 4), J. Geogr. Surv. Inst., 118, 1-8 (in Japanese).

Nishimura, T., 2011. Back-arc spreading of the northern Izu-Ogasawara (Bonin) Island arc clarified by GPS data, Tectonophys, 512, 60-67.

Nishimura, T., 2014. Short-term slow slip events along the Ryukyu Trench, southwestern Japan, observed by continuous GNSS, Prog. Earth Planet. Sci., 1(1), 22, doi:10.1186/s40645-014-0022-5.

Okada, Y., 1992. Internal deformation due to shear and tensile faults in a half-space, Bull. seism. Soc. Am., 82, 1018-1040.

Outerbridge, K.C. et al., 2010. A tremor and slip event on the CocosCaribbean subduction zone as measured by a global positioning system (GPS) and seismic network on the Nicoya Peninsula, Costa Rica, J. geophys. Res., 115, B10408, doi:10.1029/2009JB006845.

Ozawa, S., 2014. Shortening of recurrence interval of Boso slow slip events in Japan, Geophys. Res. Lett., 41, 2762-2768.

Ozawa, S., Miyazaki, S., Hatanaka, Y., Imakiire, T., Kaidzu, M. \& Murakami, M., 2003. Characteristic silent earthquakes in the eastern part of the Boso Peninsula, Central Japan, Geophys. Res. Lett., 30(6), 1283, doi:10.1029/2002GL016665.

Ozawa, S., Suito, H. \& Tobita, M., 2007. Occurrence of quasi-periodic slowslip off the east coast of the Boso peninsula, Central Japan, Earth Planets Space, 59, 1241-1245.

Tamaki, K., 1985. Two modes of back-arc spreading, Geology, 13, 475-478.

Uyeda, S. \& Kanamori, H., 1979. Back-arc opening and the mode of subduction, J. geophys. Res., 84, 1049-1061.

Wallace, L.M., Beavan, J., Bannister, S. \& Williams, C., 2012. Simultaneous long-term and short-term slow slip even at the Hikurangi subduction margin, New Zealand: implications for processes that control slow slip event occurrence, duration, and migration, J. geophys. Res., 117, B11402, doi:10.1029/2012JB009489.

Yokota, Y., Ishikawa, T., Watanabe, S., Tashiro, T. \& Asada, A., 2016. Seafloor geodetic constraints on interplate coupling of the Nankai Trough megathrust zone, Nature, 534, 374-377.

Yoshioka, S., Matsuoka, Y. \& Ide, S., 2015. Spatiotemporal slip distributions of three long-term slow slip events beneath the Bungo Channel, southwest Japan, inferred from inversion analyses of GPS data, Geophys. J. Int., 201, $1437-1455$.

Zumberge, J.F., Heflin, M.B., Jefferson, D.C., Watkins, M.M. \& Webb, F.H., 1997. Precise point positioning for the efficient and robust analysis of GPS data from large networks, J. geophys. Res., 102, 5005-5017. 